\title{
Patterns and Causes of Health Inequalities in Later Life: a Bourdieusian Approach
}

\begin{tabular}{|r|l|}
\hline Journal: & Sociology of Health and Illness \\
\hline Manuscript ID: & SHI-00330-2013 \\
\hline Manuscript Type: & Original Article \\
\hline Key Words: & $\begin{array}{l}\text { health, objective class, longitudinal path analysis, subjective class, } \\
\text { Bourdieu }\end{array}$ \\
\hline \multirow{10}{*}{ Abstract: } & $\begin{array}{l}\text { This study explores the relationship between social class and health change } \\
\text { in older people in a path analysis, using data from the English Longitudinal } \\
\text { Study of Ageing (n=6241). Our path model includes both the occupational } \\
\text { and secondary characteristics of objective social class that Bourdieu } \\
\text { describes in Distinction (1979) as well as a measure of subjective social } \\
\text { class. We investigate the direct, indirect and total effects of the predictors } \\
\text { on change in three health outcomes (self-rated health; number of } \\
\text { symptoms of depression; and number of difficulties with activities of daily } \\
\text { living). }\end{array}$ \\
$\begin{array}{l}\text { The analysis adds to the body of Bourdieusian research by showing how } \\
\text { the effects of objective social class on health are partially mediated by } \\
\text { perceived social status. It also adds to substantive research on the } \\
\text { relationship between class and health by suggesting that class-related } \\
\text { health inequalities do persist for older people, even for those who are not } \\
\text { in paid employment. It suggests that a large amount of the effect of } \\
\text { occupation on the health of older people is not direct but indirect - through } \\
\text { their personal wealth and lifestyle. } \\
\text { Word count: } \\
\text { Abstract = 178 } \\
\text { Main body including } 2 \text { tables, } 1 \text { figure and bibliography = 7844 }\end{array}$ \\
\hline
\end{tabular}


Epidemiology has set the agenda for health inequalities research, with work based on a conception of class as labour relations, operationalised through measures of occupational class (Higgs and Scambler 1998; Bolam, Murphy and Gleeson 2004; Roelfs et al. 2011). Occupational class is less theoretically robust in defining life chances once people reach state pension age and a majority cease to be in paid employment. Indeed, the retired have been excluded from much class analysis, including that exploring health inequalities (Borrell et al. 2010; Kavanagh et al. 2010; Lahelma et al. 2010; Malmusi, Borrell and Benach 2010; Vanroelen et al. 2010; Nishimura 2011; Rosenfield 2012), although recent class analysis does include retired people (Demakakos et al. 2008; Huijts, Eikemo and Skalicka 2010; McMunn et al. 2009; Prus 2011; Zimmer and Prachuabmoh 2012).

It is reasonable to suppose that, in addition to the effects of material circumstances and the specific occupational characteristics that marked their social position during working life, the lifestyle characteristics of retired people affects their health status (Poortinga, Dunstan and Fone 2007; Schau, Gilly and Wolfinbarger 2009; Scherger, Nazroo and Higgs 2011). The aim of this investigation is to explore whether lifestyle characteristics are important to the health status of people in later life, using panel data from the English Longitudinal Study of Ageing (ELSA).

\section{BACKGROUND}

\section{Objective Social Class}

Our analysis is influenced by Bourdieu (1979). Bourdieu argues that status in the class structure is dependent not only on relations within labour markets but also has a symbolic dimension that is related to consumption patterns (Chan and Goldthorpe, 2007:169). He drew a distinction between the "pertinent" occupational characteristics by which people are 
classified (Bourdieu, 1979:102) and secondary properties of class that relate to social background and lifestyle.

These secondary properties exist as economic, cultural and social capitals (Bourdieu 1986). Economic capital comprises assets that can be directly converted into money (such as houses and stocks and shares). In the context of health "possibilities" (Bourdieu 1992:206), the possession of sufficient wealth may determine the material conditions of life and make it possible for individuals to access private health-related services that may improve their health or mitigate disease.

Cultural capital is embodied in highbrow cultural and material tastes (Bourdieu, 1986:47). To "appropriate" cultural capital, one must possess the means to "consume" cultural and material goods, including sufficient physical energy, knowledge and competencies (Bourdieu 1986:50). Lifestyle habits link cultural capital to health status and: "the body is the most indisputable materialization of class taste" (Bourdieu, 1979:190). The link between exercise habits and class was tested by Engstrom in her Swedish longitudinal research (2008). She found that habits of middle age were related to cultural capital acquired in childhood.

Social capital is gained through membership of social groups, personal and formal. Bourdieu (1986:51) argues that "durable" social networks give access to the collective capital of recognition and support. Supportive networks may have a direct link to health status through the mutual support and shared experience between members that they bring. Networking activities may also confer high perceived social status and, in this way, affect health indirectly. In research, intensity of participation in social and civic networks are widely used as a measure of social capital (Putnam 1993; Carpiano 2006; Ellaway and Macintyre 2007; Murayama, Fujiwara and Kawachi 2012; Nyqvist and Forsman 2012) and there is some evidence that this is directly beneficial to health (Helliwell and Putnam 2004; Schultz et al. 2008; Snelgrove 2009; Giordano and Lindstrom 2010). 


\section{Subjective Social Status}

Following Cockerham (2005:55), the consumption patterns reflected in cultural and social capital may be linked to health at least in part through the perception that individuals have of their social status. This connects to Bourdieu's own argument. He suggests links between economic capital, cultural capital and perceived social status in his discussion of the "natural distinction" of the bourgeois (1979:57).

We include a measure of subjective social status (SSS) that derives from the psychosocial hypothesis that relative socioeconomic status is important for health in addition to absolute socioeconomic circumstances (Wilkinson 1996). In research, SSS is linked to health status through the low grade chronic stress ("status syndrome") of those at the bottom of the social hierarchy (Marmot, 2004) and is significantly associated with health status, independently of objective economic indicators (Adler et al. 2000; Ostrove et al. 2000; Singh-Manoux 2003; Demakakos et al. 2008; Rablen and Oswald 2008; Theodossiou and Zangelidis 2009; Sakurai et al. 2010; Shankar, McMunn and Steptoe 2010; Reitzel et al. 2011; Netuveli and Bartley 2012).

\section{Research Questions}

We formulated the following research questions:

- How far is the relationship between occupational class and health direct and how far mediated by cultural, social and economic capitals?

- Is the association between occupational class and health mediated via SSS?

- Is the association between wealth and health mediated, at least in part, via cultural and social capital?

- Are cultural and social capitals associated with health status via SSS? 


\section{DATA AND METHODS}

Data

ELSA is a panel study of men and women aged 50 or older drawn from sample members from the Health Survey for England. The first wave of ELSA (2002-3) had an individual response rate of 67 percent and sampled over 12,000 men and women. We used data from the first five waves (2002 to 2011 inclusive). The sample was refreshed at waves 3 and 4 to maintain the representation of people aged 50-53 years (Steptoe et al. 2012).

This is a longitudinal analysis of the same respondents at different time points so that the predictor variables are at an earlier time point than the health outcome variables. The sample includes all respondents who took part in ELSA Wave 1 who were still respondents in Wave $5(n=6241)$.

\section{Outcome Variables}

Our aim was to choose variables that expressed different aspects of health. We rejected measures of specific physical conditions (such as diabetes or ischaemic heart disease) or that were absent in some waves. Our measures were: self-rated health; number of difficulties with activities of daily living (ADLs); and number of symptoms of depression.

Response categories for self-rated health were 'excellent', 'very good', 'good', 'fair', and 'poor'. The ADL score aggregated responses from dichotomous measures of difficulties with: bathing or showering; dressing; getting in and out of bed; walking across a room; using the toilet; and eating meals. The symptoms of depression score aggregated responses from questions in the CESD-8 depression scale about whether, within the last week, respondents felt: depressed; that things were an effort; slept badly; were happy; were lonely; enjoyed life; felt sad; and could not get going (for details of CESD-8: Blazer et al. 1991; Kohout et al. 1993). 
These variables were treated as continuous in the path models. However, they were dichotomised for the descriptive analysis of their relationship with occupational class. For self-rated health, fair or poor health became one category and excellent, very good and good health became the other category. For ADL difficulties, respondents with no difficulties were separated from those with difficulties (Lynch, Brown and Harmsen 2003). For depression, respondents with four or more symptoms were separated as depressed from those with fewer symptoms (Blazer et al. 1991; Kohout et al. 1993; Steffick 2000).

\section{Predictor Variables}

Social class was assessed in this analysis using: occupational class; wealth; five measures of cultural capital; three measures of social capital; and a measure of SSS. For occupation, NSSEC (National Statistics Socio-Economic Classification) was chosen because it classifies in terms of working relations and conditions and corresponds to the primary aspect of social class for Bourdieu (see Goldthorpe 2000:206). We used the three class version of NS-SEC with categories of: managers and professionals; intermediate; and routine. This is the only derivation of NS-SEC that "may be assumed to involve a sort of hierarchy" and allows comparison between high and low occupational class (ONS 2010:Section 7) . Many researchers use it (for example: Henz, 2004; Croxford and Paterson, 2006; Csedo, 2008; Rowe et al, 2008; Jackson, 2012; Khattab, 2012; Thomas et al, 2012 and Scourfield et al, 2013 although it has been criticised for its lack of detail by Rose et al (2005:22). The measure used for work status is: paid work $(\mathrm{Y} / \mathrm{N})$.

Economic capital is operationalised as total non-pension wealth for the benefit unit. It includes all wealth held by a household in financial assets, property, other physical assets and the assets of any business they own and is measured net of any outstanding debts (Crawford and Tetlow, 2010:15). We hypothesise that wealth may be linked to health status directly, 
through material benefits and indirectly via SSS. It may also give access to cultural goods that must be privately financed, such as theatre-going. The wealth variable was scaled using $£ 100,000$ units to make the unstandardised effects easier to discern.

Cultural capital includes both tastes and activities. Participation in highbrow cultural activities is often used as a proxy for cultural capital in quantitative studies (Wildhagen, 2009; Meier Jaeger, 2011; Byun et al. 2012). In this secondary analysis, we are limited by the variables available in ELSA. Measures include engagement in both cultural and health behaviours. Cultural participation is measured by the frequency of visits to museums and galleries, to theatres and opera, and to the cinema. Responses were categorised within a sixpoint scale, ranging from 'never' to 'twice a month or more'. We also include health behaviours: smoking (Y/N); and frequency of alcohol consumption (a six-point scale from 'not at all' to 'twice a day or more').

Social capital is measured using three different networks: the number of close relationships with family and friends, excluding spouse and children; committee membership, $\mathrm{Y} / \mathrm{N}$; and frequency of volunteering measured using a four-point scale from 'less than once a year or never' to 'twice a month or more'. Again, this range of variables is dependent on the available secondary data.

SSS was assessed using the MacArthur scale, conceptualised as a ten-rung ladder. Respondents were asked to mark a cross on a rung:

Think of this ladder as representing where people stand in our society. At the top of the ladder are the people who are the best off - those who have the most money, most education, and best jobs. At the bottom are the people who are the worst off - who have the least money, least education, and the worst jobs or no jobs.

Ladder score ranged from 1 (bottom rung) to 10 (top rung). 


\section{Attrition}

Our sample of respondents who continued from Wave 1 to 5 was slightly different in profile to respondents who dropped out. The retained cohort was slightly younger than the full Wave 1 sample (mean age of 62.78 years compared to the full sample mean age of 65.27 years). They were also of higher occupational class $(34.1 \%$ in managerial and professional occupations compared to the full Wave 1 sample of $29.8 \%$ ) and also slightly healthier in Wave 1, with a higher proportion who rated their health as "excellent" (15.4\% compared to $13.2 \%$ in the full sample).

\section{Analytic Strategy}

We used path analysis to explore the total, direct and indirect effects of predictor variables on a range of health outcomes. In this analysis, the predictor variables were lagged at an earlier time point than the outcome variables (Mertler and Vannatta 2001:199) and were taken from ELSA wave 1. For the outcome variables, we focussed on the worst outcome regardless of recovery between waves 2 to 5 (in the case of self-rated health the wave 3 variable was not used because it had different response options).

We expected that the most important pathways linking the cultural participation variables to the health outcome variables would be mediated by their effect on the SSS of respondents. We did, however, add paths directly to the health outcome variables in order to cover every possible option in terms of effects.

There is an issue about the direction of causality between predictors in the model, because the predictors are all from the same time point. We theorise that the secondary characteristics of objective class, such as wealth, cultural participation and social participation, derive from 
occupational class rather than the reverse. Following Bourdieu, we also suggest that people's perceptions of their social status are the result of their objective social class.

In whichever direction/s causality is theorised to run, it remains the case that the most important associations in this analysis are those between the predictors and the health outcome variables. In this longitudinal analysis, the direction of causality is largely resolved because the health outcomes are from a later time point than the predictors and models are adjusted for baseline health scores.

The control variables of sex, age, age ${ }^{2}$ (to take account of the quadratic relationship of age with health status), and baseline health status, were lagged from wave 1 . This longitudinal approach provides a "parsimonious estimate" of the effect of the predictors on health status, because it removes any prior effect of the predictors on health, as well as any prior effect of health on the predictors (Nazroo 2011:234). It understates effects in two ways: by attending to health change over a short time period only; and by controlling for some of the effect of occupational class on health that may have occurred earlier in the life course.

A correlation matrix was produced to check for multicollinearity between variables. There was no substantial multicollinearity $(>.7$ or $<-.7)$ except between age and age ${ }^{2}$. In the path models, double-headed paths were added between these two variables and this improved model fit.

This analysis was done using Amos. Amos computes path coefficients based on linear regression. This assumes that measured variables are continuous. In this analysis, some variables are measured at an ordinal level and the assumption is made that they are latent continuous variables in which each category is a threshold, based on Fidell and Tabachnick: "the trick is to produce reasonable values for these types of variables for analysis" (2007:729). 
We used Bollen-Stine bootstrapping to correct for non-normality in the sample data. This will not work with missing data so missing values were imputed (regression imputation). We estimated goodness of fit using the root mean square error of approximation (RMSEA). This compares the model to the saturated model. It is the only index appropriate to sample sizes greater than 2000. RMSEA values larger than .10 are considered to be indicative of poorfitting models, although opinions do vary (Browne and Cudeck 1993; MacCallum, Browne and Sugawara 1996; Steiger 2000; Chen et al 2008). The Bentler-Bonett normed fit index (NFI) was used as a comparator. It compares the chi-square value of the model to the independent model. High values (greater than 0.95) are indicative of a good-fitting model.

There were large residual variances between the cultural capital variables and between the social capital variables. It is reasonable to allow the residual covariances for the cultural and social capital variables to be estimated, because the observed variables may be viewed as indicators of underlying latent variables. Double-headed paths were, therefore, added between these residual covariances.

\section{RESULTS \\ Predictor profiles}

The sample was fairly equally distributed between the three occupational classes with $34 \%$ managers and professionals and $41 \%$ routine workers. The median wealth of households in $2002 / 03$ was $£ 152,711.20 \%$ of respondents had household wealth below $£ 50,000$ and $10 \%$ had wealth over $£ 500,000$. Over one-third of the sample was in paid employment.

For SSS, responses clustered around the middle of the scale. Over one-quarter of the sample visited the theatre or opera every few months or more frequently. Fewer respondents went to museums or galleries, or visited the cinema over the same time period. Just over onethird were committee members and nearly thirty percent volunteered at least once a year. The 
mean size of respondents' personal networks was just under five persons. One-sixth of the sample smoked and under ten percent abstained from alcohol.

\section{Class Inequalities}

Table 1 shows that significant class inequalities in health persist in later life. People whose main occupation during their working lives was routine were more than twice as likely as people from managerial or professional backgrounds to report fair to poor health, with slightly smaller class differences for ADL difficulties and symptoms of depression. Forty percent of the sample reported their worst health score to be poor or fair, over one-third reported having difficulty with one or more ADLs, but only one-twentieth of the sample had four or more symptoms of depression.

\section{///TABLE 1 ABOUT HERE///}

\section{Unstandardised direct Effects}

Figure 1 shows regression coefficients for each of the paths in our models. The positive coefficients reflect associations between 'good' values for predictors and outcome variables. For example, symptoms of depression (0-8 symptoms) is coded inversely and high scores reflect few or no symptoms.

As expected, the control variables, age, age ${ }^{2}$, gender and health status at wave 1 , had the largest effects on the health outcome variables. For this sample, occupational class has an independent small direct effect on subsequent self-rated health, when controlling for baseline health. In contrast, class had no independent relationship with the number of ADL difficulties that respondents had, or their symptoms of depression. 
Class showed independent effects on wealth, on SSS, on cultural and civic participation and on smoking. When occupational class rose by one category, respondent total wealth rose by over $£ 100,000$.

Museum/gallery-going rose by nearly one-sixth for respondents from the managerial and professional class when compared to those from routine occupations, with similar effects for theatre/opera-going and for cinema attendance. The same pattern was found for volunteering, although the effect was weaker. Managers and professionals in the sample were twenty percent more likely to be committee members than were routine and manual workers. The SSS of managers and professionals was eight percent higher overall than for routine workers. They were also ten percent less likely to smoke but more likely to consume alcohol frequently.

Wealth had independent direct effects on a range of variables. It had a small positive effect on self-rated health and was likely to reduce the number of symptoms of depression that respondents had. It had no direct effect on in the number of ADL difficulties. Wealthier respondents were more likely not to smoke, to consume alcohol more frequently, to have higher SSS, to engage in cultural activities more frequently and to be volunteers or committee members.

Work also had an independent effect on health, overall. The greatest effect for the three health outcomes was on self-rated health. Having a job increased self-rated health by two percent and conferred a four percent increase in SSS.

SSS had a direct independent effect on all health outcomes when controlling for health at baseline. Respondents at the top of the status ladder had nine percent better self-rated health overall than those at the bottom. They also had four percent fewer ADL difficulties and five percent fewer symptoms of depression. 
The cultural and social participation variables had few independent direct associations with health outcome. Going regularly to museums, art galleries, or the cinema had positive effects on respondents' self-rated health. Volunteering and the size of social networks had positive effects on the number of symptoms of depression reported.

Cultural participation also had an independent effect on SSS. Increasing the frequency of theatre-going and museum attendance by one category predicted just over one percent increase in SSS. Being a committee member increased SSS by just under two percent. The size of the social network of respondents also had a very small independent effect on SSS.

Smoking, as one might expect, had an independent effect on health. It accounted for over three percent of self-rated health score and around one and a half percent of the scores for ADL difficulties and depression. Respondents who smoked were likely to have two and a half percent lower SSS than non-smokers.

\section{///FIGURE 1 ABOUT HERE//}

\section{Standardised Effects}

Table 2 compares standardised direct and indirect effects on health. The path model for selfrated health explained 36.3 percent of its variability and was a moderately reasonable fit with RMSEA $=.081$ and NFI $=.961$. The path model for ADL difficulties accounted for 39.2 percent of variance with a RMSEA score of .074 and NFI of .967. For depression, the predictors accounted for 27 percent of variance and the model was a reasonable fit with RMSEA $=.077$ and NFI $=.963$. In general, the predictors had the strongest total effects in relation to self-rated health. They had a slightly weaker effect on the number of symptoms of depression that respondents had and the weakest effects were on their number of ADL difficulties, when controlling for health at baseline. 
Class was the most important predictor of health status overall. It had a significant direct effect only on self-rated health, where the direct path accounted for one-third of the total effect. Most of the effect of class for all three health outcomes was indirect, with the most important paths operating via wealth, cultural participation and SSS. Class had a much greater indirect effect on self-rated health than it did on the other two health outcomes.

Wealth had a similar profile in its effects to class, but with important direct effects on all three health outcomes - around one half of its total effect. The direct effect of wealth presupposes indirect effects via a range of material factors that promote good health, but are missing in this model (such as good housing and diet). The most important indirect effect of wealth on all three health outcomes in this model was via SSS.

Working status had a total effect on health that was comparable to wealth, but most of its effects were direct. SSS was an important predictor of changes in health with a direct effect around one-quarter greater than wealth for all health outcomes. Most of the other predictors had non-significant direct effects. An exception is smoking, with a total effect on all health outcomes that was only slightly less than that of wealth.

The cultural participation variables had moderate effects on the self-rated health of respondents that ranged from 30 percent to 55 percent that of wealth and 18 to 55 percent of class, when controlling for health at baseline. Their separate effects on number of ADL difficulties and number of symptoms of depression for this sample were less consistent and generally weaker. In combination, the total effect of these cultural participation variables on health was relatively large. For self-rated health and the number of ADL difficulties of respondents, the total effect of cultural participation was more than the effect of wealth and nearly as much as the effect of class. The effect on the number of symptoms of depression was similar but smaller. 
The effects of social participation on health were smaller. Being a volunteer and having a larger personal network did have a moderate direct effect in reducing symptoms of depression. These effects were half the direct effects of working, but larger than those from any other predictor.

\section{///TABLE 2 ABOUT HERE//}

\section{DISCUSSION}

This longitudinal path analysis of health change in older people includes measures of objective and subjective social class. It adds to research on the links between occupation and health (Foraker et al. 2011) and to work that found subjective measures of class to be equally or more strongly related to health than objective measures of socioeconomic position (Dunn, Veenstra and Ross 2006) or more (Adler et al. 2000; Ostrove et al. 2000; Singh-Manoux, Adler and Marmot 2003; Demakakos et al. 2008).

The analysis suggests that class-related health inequalities do persist for people who are near or in retirement. For this group, occupational class appears to have most effect via accumulated material resources that are used to arrange their lives. There is also a strong independent link between wealth and health inequalities via SSS. This suggests that the relationship seen here between SSS and health has some of its origin in material inequalities. As Freund (2006) has argued, material environments may influence the body both materially and as a source of psychosocial stress (also Hoffman 2011). Davidson, Kitzinger and Hunt (2006) have shown how awareness of class and material living circumstances impact on perceptions of status, hierarchies and social comparisons at the individual level (also Bolam, Murphy and Gleeson, 2004).

In this analysis social capital appears to be less important for health than economic and cultural capital. Volunteering and having a large network of family and friends do appear to 
have a protective effect in relation to depression and this is confirmed by previous research. Song (2011) found a strong inverse relationship between social participation and psychological distress. De Jong Gierveld and Dykstra (2008) found an inverse relationship between the number of family generations supported and loneliness in older people.

This analysis of pathways between health and economic and social inequalities adds to research that explores multiple aspects of stratification and health inequalities (McDonough, Worts and Sacker 2010; Mackenbach 2012). We have assessed effects from predictors relatively using comparators that have well-evidenced relationships with health status, such as economic class and wealth. Our findings point to a conception of social class that goes beyond economic class, one that is the product of processes of stratification operating across social domains, such as the economy, culture and civil society. In order to understand inequalities in health we need to come to terms with this wider nexus of material and social inequalities and to explore further these processes of stratification.

If the health status of older people is partly the result of structural factors that operate in cultural and civic domains then the provision of public resources to encourage cultural and social participation more widely will have positive health effects. There are ten million people in the UK over 65 years old (one in six people). In 2007/08, the average care bill for NHS services to retired households was over $£ 5,000$ per household per year (www.parliament.uk). In this context, if the government want to reduce costs to the NHS from ill-health in the elderly, it might be good policy (even in a recession), to reconsider the evidence for cutting subsidies to museums, theatre groups and sports activities. 


\section{REFERENCES}

Adler, N. E., Epel E. S., Castellazzo, G. and Ickovics, J. F. (2000) Relationship of subjective and objective social status with psychological and physicological functioning: preliminary data in healthy white women, Health Psychology, 19, 586-92

Blazer, D. G., Burchett, B. B., Service, C. and George, L. K. (1991) The association of age and depression among the elderly: an epidemologic exploration, Journal Gerontology, $46,6, \mathrm{M} 210-15$

Bolam, B., Murphy, S. and Gleeson, K. (2004) Individualisation and inequalities in health: a qualitative study of class identity and health, Social Science and Medicine, 59, 1355-65

Borrell, C., Muntaner, C., Gil-Gonzalez, D., Artazioz, L., Rodriguez-Sanz, M., Rohlfs, I., Perez, K., Garcia-Calvente, M., Villegas, R. and Alvarez-Dardet, C. (2010) Perceived discrimination and health by gender, social class and country of birth in a Southern European country, Preventive Medicine, 50,1, 86-92

Bourdieu, P. (1979) Distinction: a Social Critique of the Judgement of Taste. (2006 rpt.). Translated by R. Nice. Abingdon:Routledge

Bourdieu, P. (1986) The forms of capital. In Richardson, J. G. (ed) Handbook of Theory of Research for the Sociology of Education (Chapter 2). New York:Greenwood

Bourdieu, P. (1992) The Rules of Art: Genesis and Structure of the Literary Field. (1996 rpt.). Translator Emanuel, S., California:Stanford University

Browne, M. W., Cudeck, R. (1993) Alternative ways of assessing model fit . In K. Bollen and J. Long (eds) Testing Structural Equation Models. Newbury Park:Sage. pp. 136-62

Byun, S.-Y., Evan, S. and Kyung-Keun, K. (2012) Revisiting the role of cultural capital in East Asian educational systems: the case of South Korea, Sociology of Education, 85, 219-240 
Carpiano, R. M. (2006) Toward a neighbourhood resource-based theory of social capital for health: can Bourdieu and sociology help?, Social Science and Medicine, 62, 165-75

Chan, T. W. and Goldthorpe, J. H. (2007) Social stratification and cultural consumption: the visual arts in England, Poetics, 35, 168-190

Chen, F., Curran, P. J., Bollen, K. A., Kirby, J. and Paxton, P. (2008) An empirical evaluation of the use of fixed cutoff points in RMSEA test statistic in structural equation models, Sociological Methods Research, 36,4, 462-94

Cockerham, W. (2005) Health lifestyle theory and the convergence of agency and structure, Journal of Health and Social Behavior, 46, 51-67

Crawford, R. and Tetlow, G. (2010) Employment, retirement and pensions. In Banks, J., C. Lessof, Nazroo, J., Rogers, N., Stafford, M. and Steptoe, A. (eds), Financial Circumstances, Health and Well-being of the Older Population in England: The 2008 English Longitudinal Study of Ageing (Wave 4). London:The Institute for Fiscal Studies. pp. $11-75$

Croxford, L. and Paterson, L. (2006) Trends in social class segregation between schools in England, Wales and Scotland since 1984, Research Papers in Education, 21,4, 381-406

Csedo, K. (2008) Negotiating skills in the global city: Hungarian and Romanian professionals and graduates in London, Journal Ethnic and Migration Studies, 34, 5, 803-23

Davidson, R., Kitzinger, J. and Hunt, K. (2006) The wealthy get healthy, the poor get poorly? Lay perceptions of health inequalities, Social Science and Medicine, 62, 2171-82

De Jong, G. J. and Dykstra, P. A. (2008) Virtue is its own reward? Support-giving in the family and loneliness in middle and old age, Ageing and Society, 28, 2, 271-87

Demakakos, P., Nazroo, J., Breeze, E. and Marmot, M. (2008) Socioeconomic status and health: the role of subjective social status, Social Science and Medicine, 67, 330-40 
Dunn, J. R., Veenstra, G. and Ross, N. (2006) Psychosocial and neo-material dimensions of SES and health revisited: predictors of self-rated health in a Canadian national survey, Social Science and Medicine, 62, 1465-73

Ellaway, A. and Macintyre, S. (2007) Is social participation associated with cardiovascular disease risk factors?, Social Science and Medicine, 64, 1384-91

Engstrom, L.-M. (2008) Who is physically active? Cultural capital and sports participation from adolescence to middle age - a 38-year follow-up study, Physical Education and Sport Pedagogy, 13, 4, 319-43

Foraker, R. E., Rose, K. M., Chang, P. P., McNeill, A. M., Suchindran, C. M., Selvin, E. and Rosamond, W. D. (2011) Socioeconomic status and the trajectory of self-rated health, Age and Ageing, 40, 706-11

Freund, P. (2006) Socially constructed embodiment: neurohormonal connections as resources for theorizing about health Inequalities, Social Theory and Health, 4, 85-108

Giordano, G.N. and Lindstrom, M. (2010) The impact of changes in different aspects of social capital and material conditions on self-rated health over time: a longitudinal cohort study, Social Science and Medicine, 70, 700-10

Goldthorpe, J. H. (2000) On Sociology: Numbers, Narratives and the Integration of Research and Theory. Oxford:Oxford University Press

Helliwell, J.F. and Putnam, R. (2004) The social context of wellbeing, Proceedings of the Royal Society B:Biological Sciences, 359, 1435-46

Henz, U. (2004) The effects of informal care on paid-work participation in Great Britain: a lifecourse perspective, Ageing and Society, 24, 06, 851-80

Higgs, P. and Scambler, G. (1998) Explaining health inequalities: how useful are concepts of social class? In Scambler, G. and Higgs, P. (eds), Modernity, Medicine and Health: Medical Sociology Towards 2000. London:Routledge. pp. 82-99 
Hoffman, R. (2011) Socioeconomic inequalities in old-age mortality: a comparison of Denmark and the USA, Social Science and Medicine, 72, 12, 1986-92

Huijts, T., Eikemo, T. A. and Skalicka, V. (2010) Income-related health inequalities in the Nordic countries: examining the role of education, occupational class and age, Social Science and Medicine, 71, 11, 1964-72

Jackson, M. (2012) Bold choices: how ethnic inequalities in educational attainment are suppressed, Oxford Review of Education, 38, 2, 189-208

Khattab, N. (2012) 'Winners' and 'losers': the impact of education, ethnicity and gender on Muslims in the British labour market, Work, Employment and Society, 26, 556-73

Kavanagh, A., Bentley, R. J., Turrell, G., Shaw, J., Dunstan, D. and Subramanian, S.V. (2010) Socioeconomic position, gender, health behaviours and biomarkers of cardiovascular disease and diabetes, Social Science and Medicine, 71, 6, 1150-60

Kohout, F. J., Berkman, L. F., Evans, D. A. and Cornoni-Huntley, J. (1993) Two shorter forms of the CES-D depression symptoms index, J Ageing and Health, 5, 2, 179-93

Lahelma, E., Lallukka, T., Laaksonen, M., Martikainen, P., Rahkonen, O., Chandola, T., Head, J., Marmot, M., Kagamimori, S., Tatsuse, T. and Sekine, M. (2010) Social class differences in health behaviours among employees from Britain, Finland and Japan: the influence of psychosocial factors, Health and Place, 16, 1, 61-70

Lynch, S. M., Scott Brown, J. and Harmsen, K. G. (2003) The effect of altering ADL thresholds on active life expectancy estimates for older persons, Journal Gerontology Soc Sci, 58, 3, S171-8

MacCallum, R. C., Browne, M. W. and Sugawara, H. M. (1996) Power analysis and determination of sample size for covariance structure modelling, Psychological Methods, $1,130-49$ 
Mackenbach, J. P. (2012) The persistence of health inequalities in modern welfare states: the explanation of a paradox, Social Science and Medicine, 75, 4, 761-9

Malmusi, D., Borrell, C. and Benach, J. (2010) Migration-related health inequalities: showing the complex interactions between gender, social class and place of origin, Social Science and Medicine, 71, 9, 1610-19

Marmot, M. G. (2004) Status Syndrome: How Your Social Standing Directly Affects Your Health and Life Expectancy. London:Bloomsbury.

McDonough, P., Worts, D. and Sacker, A. (2010) Socioeconomic inequalities in health dynamics: a comparison of Britain and the United States, Social Science and Medicine, $70,2,251-60$

McMunn, A., Nazroo, J. and Breeze, E. (2009) Inequalities in health at older ages: a longitudinal investigation of onset of illness and survival effects in England, Age and Ageing, 181-87

Meier Jaeger, M. (2011) Does cultural capital really affect academic achievement? New evidence from combined sibling and panel data, Sociology of Education, 84, 281-99

Mertler, C. A. and Vannatta, R. A. (2001) Advanced and Multivariate Statistical Methods: Practical Application and Interpretation. (2005 rpt), California:Pyrczak.

Murayama, H., Fujiwara, Y. and Kawachi, I. (2012) Social capital and health: a review of prospective multilevel studies, J Epidemiology, 22, 3, 179-87

Nazroo, J. (2011) Using longitudinal survey data: researching changing health in later life. In Mason, J. and Dale, A. (eds) Understanding Social Research: Thinking Creatively About Method. London:Sage. pp. 225-42

Netuveli, G. and Bartley, M. (2012) Perception is reality: effect of subjective versus objective socio-economic position on quality of life, Sociology, 46, 6, 1208-15 
Nishimura, J. (2011) Socioeconomic status and depression across Japan, Korea and China: exploring the impact of labour market structures, Social Science and Medicine, 73, 4, 604-14

Nyqvist, F. F. and Forsman, A. K. (2012) Social capital as a resource for mental well-being in older people: a systematic review, Aging and Mental Health, 1-17

ONS (2010) SOC2010 Volume 3 NS-SEC (Rebased On SOC2010) User Manual, www.ons.gov.uk/ons/guide-method/classifications/current-standardclassifications/soc2010/soc2010-volume-3-ns-sec--rebased-on-soc2010--usermanual/index.html\#7 Retrieved July 2013

ONS (2013, June) Total Household Wealth by Region and Age Group, http://www.ons.gov.uk/ons/rel/regional-trends/regional-economic-analysis/wealth-byage-group-and-region--june-2013/rep-total-household-wealth-by-region-and-agegroup.html\#tab-Wealth-of-households-that-are-home-to-adults-aged-65-or-above Retrieved July 2013

Ostrove, J. M., Adler, N. A., Kuppermann, M. and Washington, A. E. (2000) Objective and subjective assessments of socioeconomic status and their relationship to self-rated health in an ethnically diverse sample of pregnant women, Health Psychology, 19, 613-8

Poortinga, W., Dunstan, F. D. and Fone, D. L. (2007) Health locus of control beliefs and socio-economic differences in self-rated health, Preventive Medicine, 46, 374-80

Prus, S. G. (2011) Comparing social determinants of self-rated health across the United States and Canada, Social Science and Medicine, 73,1, 50-9

Putnam, R. D. (1993) Making Democracy Work: Civic traditions in Modern Italy. Princeton: Princeton University Press. 
Rablen, M. D. and Oswald, A. J. (2008) Mortality and immortality: the Nobel Prize as an experiment into the effect of status upon longevity, Journal Health Economics, 27, 6, $1462-71$

Reitzel, L. R., Businelle, M. S., Kendzor, D. E., Yisheng, L., Yumei, C., Castro, Y., Mazas, C. A., Cofta-Woerpel, L., Cinciripini, P. M. and Wetter, D. W. (2011) Subjective social status predicts long-term smoking abstinence, BMC Public Health, 11, 135-41

Roelfs, D. J., Shor, E., Davidson, K. W. and Schwartz, J. E. (2011) Losing life and livelihood: a systematic review and meta-analysis of unemployment and all-cause mortality, Social Science and Medicine, 72, 6, 840-54

Rose, D. and Harrison, E. (2007) The european socio-economic classification: a new social class schema for comparative European research, European Societies, 9, 3, 459-90

Rose, D. and Pevalin, D. J. [with O'Reilly, K.] (2005) The National Statistics SocioEconomic Classification: Origins, Development and Use. National Statistics:Palgrave Macmillan.

Rosenfield, S. (2012) Triple jeopardy? Mental health at the intersection of gender, race and class. Social Science and Medicine, 74, 11, 1791-801

Rowe, R.E., Magee, H., Quigley, M.A., Heron, P., Askham, J. and Brocklehurst, P. (2008) Social and ethnic differences in attendance for antenatal care in England, Public Health, $122,1363-72$

Sakurai, K., Kawakami, N., Yamaoka, K., Ishikawa, H. and Hashimoto, H. (2010) The impact of subjective and objective social status on psychological distress among men and women in Japan, Social Science and Medicine. 70, 1832-9

Schau, H. J., Gilly, M. C. and Wolfinbarger, M. (2009) Consumer identity renaissance: the resurgence of identity inspired consumption in retirement, Journal Consumer Research, $36,2,255-76$ 
Scherger, S., Nazroo, J. and Higgs, P. (2011) Leisure activities and retirement: do structures of inequality change in old age?, Ageing and Society, 31, 1, 146-72

Schultz, J., O’Brien, A. M. and Tadesse, B. (2008) Social capital and self-rated health: results from the US 2006 social capital survey of one community, Social Science and Medicine, $67,606-17$

Scourfield, J., Warden, R., Gilliat-Ray, S., Khan, A. and Otri, S. (2013) Religious nurture in British Muslim families: implications for social work, International Social Work, 56, 32642

Shankar, A., McMunn, A. and Steptoe, A. (2010), Health-related behaviors in older adults: relationships with socioeconomic status, American Journal of Preventive Medicine, 38, 1, $39-46$

Singh-Manoux, A., Adler, N. A. and Marmot, M. G. (2003) Subjective social status: its determinants and its associations with measures of ill-health in the Whitehall II study, Social Science and Medicine, 56, 1321-33

Snelgrove, J. W., Pikhart, H. and Stafford, M. (2009) A multilevel analysis of social capital and self-rated health: evidence from the British Household Panel Survey, Social Science and Medicine, 68, 1993-2001

Song, L. (2011) Social capital and psychological distress, Journal of Health and Social Behaviour, 52, 478-92

Steffick, D. E. (2000) Documentation of affective functioning measures in the Health and Retirement Study. HRS/AHEAD Documentation Report. The HRS Working Group, Michigan:University of Michigan

Steiger, J. H. (2000) Point estimation, hypothesis testing and interval estimation using the RMSEA: some comments and a reply to Hayduk and Glaser, Structural Equation Modeling. 7, 149-6 
Steptoe, A., Breeze, E., Banks, J. and Nazroo, J. (2012) Cohort profile: the English Longitudinal Study of Ageing (ELSA), Int. Journal Epidemiology

Tabachnick, B. G. and Fidell, L. S. (2007) Using Multivariate Statistics. Boston:Pearson.

Theodossiou, I. and Zangelidis, A. (2009) The social gradient in health: the effect of absolute income and subjective social status assessment on the individual's health in Europe, Economics and Human Biology, 7, 229-37

Thomas, C., Nightingale, C. M., Donin, A. S., Rudnicka, A. R., Owen, C. G., Sattar, N., Cook, D. G. and Whincup, P. H. (2012) Socio-economic position and type 2 diabetes risk factors: patterns in UK children of South Asian, Black African-Caribbean and White European origin, PLoS ONE, 7, 3, 1-11

Vanroelen, C., Levecque, K., Moors, G. and Louckx, F. (2010) Linking credentialed skills, social class, working conditions and self-reported health: a focus on health inequalitygenerating mechanisms, Sociology of Health and Illness, 32, 6, 948-64

Wildhagen, T. (2009) Why does cultural capital matter for high school performance? An empirical assessment of teacher-selection and self-selection mechanisms as explanations of the cultural capital effect, The Sociological Quarterly, 50, 173-200

Wilkinson, R. G. (1996) Unhealthy Societies: the Afflictions of Inequality. London:Routledge.

Zimmer, Z. and Prachuabmoh, V. (2012) Comparing the socioeconomic status-health gradient among adults 50 and older across rural and urban areas of Thailand in 1994 and 2007, Social Science and Medicine, 71, 11, 1964-72 
Table $\mathbf{1}^{1}$

\begin{tabular}{|c|c|c|c|c|}
\hline & & \multicolumn{3}{|c|}{ NS-SEC (ref. cat. = MA\&P) } \\
\hline & & $\begin{array}{c}\text { Managerial, } \\
\text { administrative \& } \\
\text { professional }\end{array}$ & Intermediate & Routine \& manual \\
\hline \multirow{3}{*}{$\begin{array}{l}\text { Reporting fair or } \\
\text { poor health }\end{array}$} & $\%$ & 25.8 & 23.9 & 50.3 \\
\hline & OR & 1.00 & 1.38 & 2.37 \\
\hline & $95 \% \mathrm{Cl}$ & & $1.522-1.236$ & $2.499-2.245$ \\
\hline \multirow{3}{*}{$\begin{array}{l}\text { Difficulty with 1+ } \\
\text { ADL }\end{array}$} & $\%$ & 27.5 & 24.3 & 48.2 \\
\hline & OR & 1.00 & 1.31 & 1.94 \\
\hline & $95 \% \mathrm{Cl}$ & & $1.447-1.177$ & $2.060-1.820$ \\
\hline \multirow{3}{*}{$\begin{array}{l}4+\text { symptoms of } \\
\text { depression }\end{array}$} & $\%$ & 25.5 & 22.0 & 52.5 \\
\hline & OR & 1.00 & 1.18 & 1.88 \\
\hline & $95 \% \mathrm{Cl}$ & & $1.396-0.960$ & $2.060-1.696$ \\
\hline
\end{tabular}

\footnotetext{
1 Source: Marmott, Michael, Z. Oldfield, S. Clemens, M. Blake, A. Phelps, J. Nazroo, A. Steptoe, N. Rogers and J. Banks. 1998-2011. The English Longitudinal Study of Ageing UK Data Service [distributor]. Pi. 10.5255/UKDASN-5050-5.
} 


\section{Figure 1}

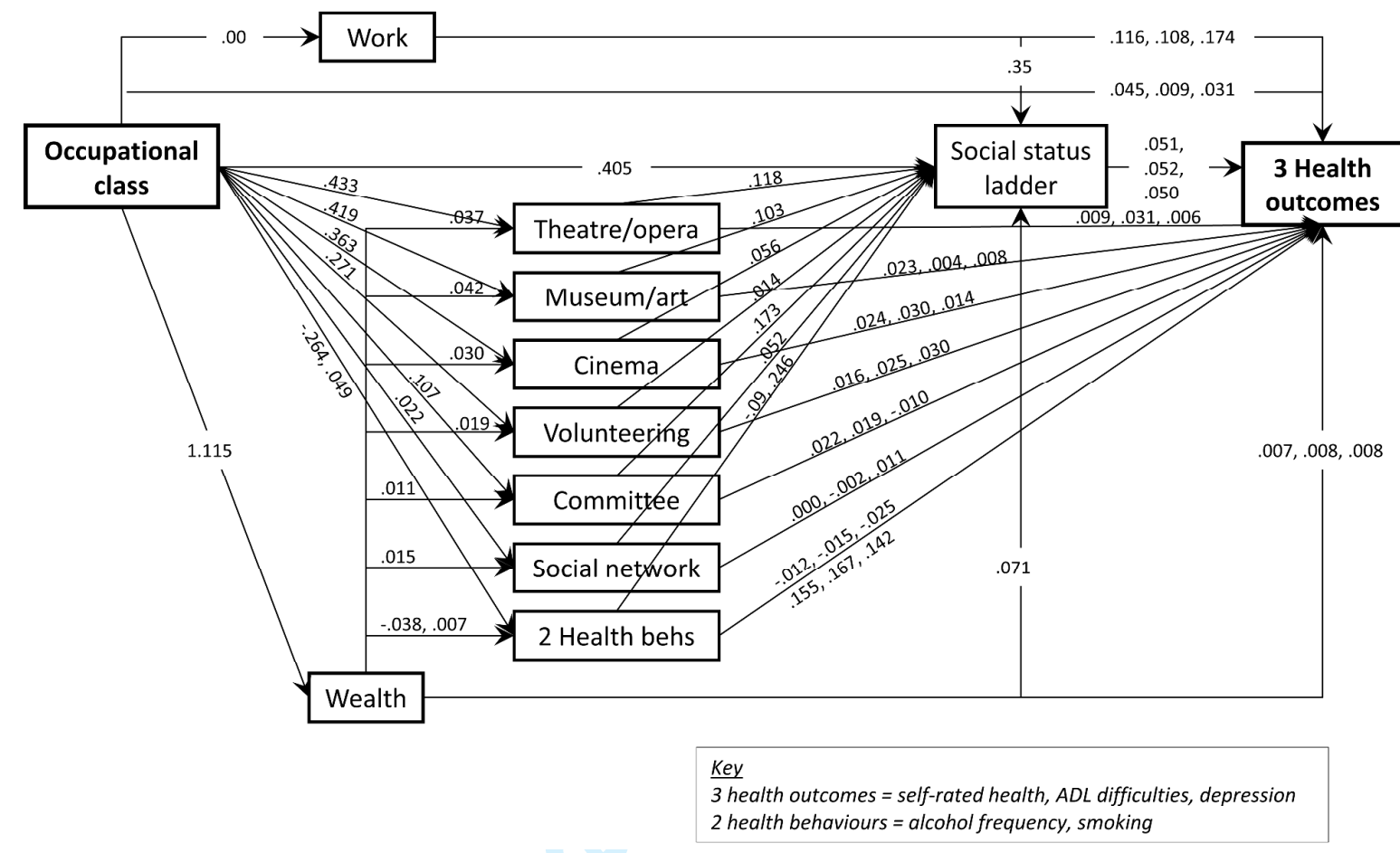




\section{Table $2^{\mathrm{i}}$}

\begin{tabular}{|c|c|c|c|}
\hline & Self-rated health & $\begin{array}{c}A D L \\
\text { difficulties }\end{array}$ & $\begin{array}{c}\text { Symptoms of } \\
\text { depression }\end{array}$ \\
\hline \multicolumn{4}{|l|}{ Class } \\
\hline Direct & .040 & .004 & .022 \\
\hline Via wealth & .016 & .009 & .012 \\
\hline Via subjective social status & .018 & .010 & .014 \\
\hline Via theatre/opera-going & .006 & .007 & .004 \\
\hline Via museum/gallery-going & .010 & .002 & .004 \\
\hline Via cinema-going & .009 & .005 & .004 \\
\hline Via volunteering & .004 & .003 & .006 \\
\hline Via committee membership & .003 & .001 & .000 \\
\hline Via social networks & .000 & .000 & .000 \\
\hline Via alcohol frequency & .004 & .002 & .005 \\
\hline Via smoking & .007 & .004 & .005 \\
\hline Via work & .000 & .000 & .000 \\
\hline Total & .117 & .048 & .076 \\
\hline Wealth & & & \\
\hline Direct & .032 & .017 & .027 \\
\hline Via subjective social status & .016 & .008 & .012 \\
\hline Via theatre/opera-going & .002 & .003 & .001 \\
\hline Via museum/gallery-going & .005 & .001 & .002 \\
\hline Via cinema-going & .003 & .002 & .002 \\
\hline Via volunteering & .001 & .001 & .002 \\
\hline Via committee membership & .002 & .001 & .000 \\
\hline Via social networks & .000 & .000 & .001 \\
\hline Via alcohol frequency & .003 & .002 & .004 \\
\hline Via smoking & .005 & .003 & .004 \\
\hline Total & .069 & .038 & .054 \\
\hline \multicolumn{4}{|l|}{ Work } \\
\hline Direct & .057 & .027 & .067 \\
\hline Via subjective social status & .009 & .005 & .007 \\
\hline Total & .066 & .032 & .074 \\
\hline \multicolumn{4}{|l|}{ Subjective social status } \\
\hline Direct & .086 & .046 & .066 \\
\hline \multicolumn{4}{|l|}{ Theatre/opera } \\
\hline Direct & .012 & .022 & .007 \\
\hline Via subjective social status & .009 & .005 & .007 \\
\hline Total & .021 & .027 & .013 \\
\hline \multicolumn{4}{|l|}{ Museum/gallery } \\
\hline Direct & .031 & .003 & .008 \\
\hline Via subjective social status & .007 & .004 & .005 \\
\hline Total & .038 & .006 & .014 \\
\hline \multicolumn{4}{|l|}{ Cinema-going } \\
\hline Direct & .034 & .022 & .015 \\
\hline Via subjective social status & .004 & .002 & .003 \\
\hline Total & .038 & .024 & .018 \\
\hline \multicolumn{4}{|l|}{ Committee } \\
\hline Direct & .011 & .005 & -.004 \\
\hline Via subjective social status & .004 & .002 & .003 \\
\hline Total & .015 & .007 & .000 \\
\hline
\end{tabular}

${ }^{\text {i }}$ Source: Marmott et al., ibid. 


\begin{tabular}{llll}
\hline & Self-rated health & $\begin{array}{c}\text { ADL } \\
\text { difficulties }\end{array}$ & $\begin{array}{c}\text { Symptoms of } \\
\text { depression }\end{array}$ \\
\hline Volunteer & & & \\
\hline Direct & .019 & .016 & .029 \\
\hline Via subjective social status & .001 & .000 & .001 \\
\hline Total & .020 & .016 & .029 \\
\hline Social network & & & \\
\hline Direct & .000 & -.004 & .026 \\
\hline Via subjective social status & .008 & .004 & .006 \\
\hline Total & .008 & .001 & .032 \\
\hline Alcohol frequency & & & \\
\hline Direct & -.017 & -.011 & -.027 \\
\hline Via subjective social status & -.007 & -.004 & -.032 \\
\hline Total & -.024 & -.014 & \\
\hline Smoking & & & .042 \\
\hline Direct & .058 & .033 & .004 \\
\hline Via subjective social status & .005 & .003 & .046 \\
\hline Total & .063 & .033 &
\end{tabular}

